\title{
Presentación del Tema Central \\ Imágenes y culturas digitales
}

\section{Presentation of the Central Theme Images and digital culture}

\author{
María Cristina Fuentes Zurita \\ Universidad Autónoma Metropolitana Iztapalapa, Ciudad de \\ México, México \\ ORCID: https://orcid.org/oooo-000I-7230-6103 \\ ISSN: ISSN-OI85-4259; e-ISSN：2007-9I76
}

DoI: http://dx.doi.org/Io.28928/revistaiztapalapa/782015/ptc/fuenteszuritamc

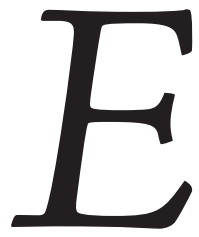

n el mundo contemporáneo, donde circulan múltiples fotografías, resulta relevante indagar sobre las imágenes que se producen. Fotografías e imágenes no son lo mismo. Se presentan además diferentes regímenes y registros visuales: unos tradicionales, sencillos; otros más actuales e intrincados. Y todos conviven gracias a la convergencia tecnológica en computadoras, tabletas electrónicas, celulares y televisión digital.

Existen discursos y formatos como el documental, el periodístico, el cinematográfico, y el de las plataformas de internet para datos visuales como Instagram y Flickr, además de Google, Yahoo, Facebook, Twitter; los de software con licencia (como Office) y otros libres. Estos lenguajes son multidimensionales, pues incorporan texto, sonido, imágenes, a veces son interactivos y se perciben en tiempo real, lo cual multiplica la función de la imagen como objeto que se observa y que también se produce y reproduce fácilmente. Esto implica ampliar 
las disposiciones y capacidades del sujeto frente a la imagen, y también provoca la modificación de las prácticas, incluidas las académicas. Así, se crean nuevas culturas digitales que invitan a incluir cada vez más recursos en aprendizajes permanentes, utilizando todos los sentidos y la experiencia. Lo anterior ha generado fenómenos nuevos de hiperconexión e hiperrelacionalidad, o comportamientos virales de contagio, así como presentaciones recurrentes del usuario con las selfies (autorretratos), nuevos regímenes autobiográficos y, a veces, hiperrepresentaciones de sí, todo aquello que se nombra como cibercultura.

La visualidad actual está fuertemente diseñada por la tecnología digital. Esta circunstancia amplía, pero también limita el campo de acción. Los sujetos que la usan son conducidos por las avenidas tecnológicas existentes, pero acaban imprimiéndole personalidades específicas a los usos y por lo tanto a los significados de las imágenes que se logran en este entorno. Las selfies son un buen ejemplo de esto, que ha generado modas masivas y desplazado el mundo analógico y sus prácticas sociales, llenas de emociones y añoranzas, tal y como lo menciona en esta entrega Rocío Rueda, e inaugurado otras tantas desde una "nueva piel digital" (Fuentes, 20II).

Ciertamente, no todo es nuevo: las ciberculturas digitales de producción de las imágenes se apropian de lo existente, incluso de lo clásico, pero lo impregnan de la visualidad contemporánea remezclada, para contribuir a la reedición de las culturas tradicionales en un nuevo orden social, donde las coordenadas del tiempo y el espacio se mueven, y muchas veces nos desconciertan. La pregunta central de este tema es: ¿Desde dónde se lee lo que se produce en la red?

Estas herramientas tecnológicas de la información y la comunicación son complicadas por la innovación, lo cual nos posiciona en un aprendizaje informal permanente, y nos enfrenta a la obsolescencia no solo tecnológica sino de los saberes como referentes de interpretación e interrelación, y eso genera a su vez nuevas experiencias subjetivas. Sabemos que la complejidad de las reacciones subjetivas, emocionales, estéticas, políticas y éticas frente al dispositivo electrónico están en el sujeto y no en las máquinas. Así lo sugirió Herbé Cochet (2008), y de ello se desprende la necesidad de estudiar la apropiación cultural y los usos humanos que de ella se hacen, así como las nuevas identidades y los imaginarios que se despliegan, y en lo presencial apoyar la formación de los sujetos.

Es por ello que en este número de Iztapalapa. Revista de Ciencias Sociales y Humanidades, fueron convocados investigadores de diversas academias a reflexionar sobre estas nuevas presencias. Aquí proponen varias miradas sobre las imágenes y las culturas digitales. Entre los ensayos que se presentan están los de Rebeca Monroy y Rocío Rueda, reconocidas cada una en su área de acción. La primera desde 
la historia del arte, especializada en la fotografía mexicana, y la segunda desde la educación digital en el sur de Latinoamérica. Por su parte, los otros dos autores -Antonio Zirión y Juan Soto- son de casa, estudian y producen imágenes desde la antropología visual y la psicología social, respectivamente.

El lector encontrará aquí un cuestionamiento a la conocida frase "Una imagen vale más que mil palabras". Para desentrañar su sentido se necesitan diversas lecturas, contextualizarlas, saber quién y por qué la produce, para qué, dónde circula, a quién va dirigida, con qué soporte tecnológico se realizó, si es original, y los diversos discursos que utiliza: texto, imagen, sonido. De ahí que las reflexiones de los investigadores invitados coincidan en la necesidad de confluencia de las academias y sus miradas, para lograr interpretarla; es decir, relaciones multi, inter y transdisciplinarias para comprender lo que acontece con la tecnología digital, como dice Monroy en su trabajo. De hecho se puede constatar que se están generando nuevos campos de conocimiento respecto del tema.

Como ejemplos podemos observar, en el número anterior de la revista, que el sociólogo y comunicólogo Francisco Javier Cortázar, de la Universidad de Guadalajara, publica el estudio de los memes y las selfies en internet, y destaca su papel en la actualización de contenidos, como muestra de una cultura digital de imágenes portadoras de leyendas urbanas.

Todos los autores presentan los avances que han desarrollado para construir discursos disciplinarios, que intentan ayudar a comprender/explicar las imágenes que se producen o que circulan desde la hegemonía de lo que aparece con mayor frecuencia en los diferentes dispositivos digitales; un rostro ensangrentado de un estudiante normalista de Ayotzinapa, un bonito atardecer en cualquier playa, la taza de café, incluso las selfies como imágenes de afirmación más que de comunicación.

En el mundo digital se multiplican por millones las imágenes y los autores son artistas, fotógrafos académicos, aficionados o simples usuarios que hacen "remixes" de canciones o fotos antiguas o cazadores de vivencias comunes, portadores de un teléfono celular o ciudadanos críticos que parodian la realidad con humor, innovando y a veces reproduciendo el régimen visual de las televisoras. Así, al mismo tiempo que se genera una vasta y homogénea cultura digital, aparecen las diferencias, y las ciencias sociales se enfrentan a esta presencia tecnológica que las lleva a profundizar y a desarrollar de manera particular sus reflexiones, prácticas de

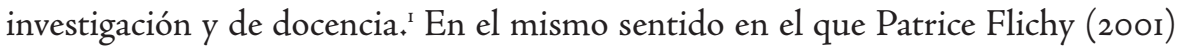

I Es sabido el gran impacto del desarrollo de la cibernética y las telecomunicaciones en el quehacer científico. No abordamos este tema. Se quiere enfatizar, en cambio, su impacto en la producción 
afirma que la tecnología toma la forma del lugar adonde llega, como puede ser un contexto histórico-cultural específico, o la experiencia de un sujeto, ocurre con la práctica disciplinaria que la estudia, como se muestra en los artículos que integran este número de esta revista.

Abre el número el artículo "Nuevos retos para los fotohistoriadores: de la fotografía analógica a la digital”, de Rebeca Monroy, quien pone en práctica algunos elementos de análisis para enriquecer los estudios de ambos tipos de imágenes. El texto nos ofrece un panorama del trabajo que la autora, fotógrafa e historiadora en esa materia, ha desarrollado con su grupo de investigación, para consolidar su campo de interés en el Seminario de la Mirada Documental. En esta ocasión aborda los regímenes visuales desde la foto de la Revolución mexicana hasta la fecha, sus formatos, temas y aportes, así como las ausencias debidas al momento político, para llegar a la biografía de los autores o de los personajes de las imágenes. Presenta una revisión de diversos aspectos de la fotografía analógica en México, estudios sobre su desarrollo social, cultural, estético, tecnológico y político, para comprender temáticas, estilos, y la documentación de acontecimientos y periodos. Abarca desde el porfiriato, cuando se introducía la fotografía en México, sus características y temas, hasta llegar al momento actual.

El siguiente artículo, "Miradas cómplices: cine etnográfico, estrategias colaborativas y antropología visual aplicada”, de Antonio Zirión Pérez, busca, al igual que el previo, aportar conocimiento en este campo. El autor traza el contexto histórico del cine documental colaborativo, inscrito en la antropología visual. ${ }^{2}$ Uno de sus intereses es subrayar las antiguas raíces de este campo en la antropología clásica; hace referencia, por ejemplo, a las imágenes que acompañaron las investigaciones de Margaret Mead y Gregory Bateson, en Bali, en los años cuarenta. Se sitúa en los derroteros de la etnografía y reconoce que, en la medida en que haya un pensamiento potente que acompañe las imágenes, estas producen verdaderos aportes para la antropología, es decir, no se trata solo de hacer fotos, filmar o documentar imágenes, sino de producir aquellas cuya lectura resulte al menos tan importante como la escritura en el estudio de las culturas. El autor insiste en la importancia de la tecnología digital como herramienta para hacer un cine más colaborativo y una antropología más aplicada, pues se trabaja desde el terreno o los espacios del sujeto que produce la cultura, quien con

y el manejo de las imágenes y cómo motiva cambios de paradigma en la construcción del conocimiento y del pensamiento científico y social.

2 Tanto en su labor docente y por medio de múltiples actividades académicas, como a través de eventos culturales, por ejemplo, el Festival Ambulante, la muestra Cine entre culturas dentro del Festival docsDF y las Jornadas de Antropología Visual. 
transferencia tecnológica puede empuñar las cámaras ligeras o utilizar su celular y hacer imágenes, tal y como lo hizo el mismo Zirión en su trabajo como codirector de los documentales Voces de la Guerrero y Fuera de foco. ${ }^{3}$ Así se genera un espacio de comunicación intercultural, asunto que no es nuevo, y lo ejemplifica con la memorable cinta Nanuk of the North (1922), del geógrafo y cartógrafo Robert Flahery, donde se presenta lo que ocurrió entre él y su amigo inuit, cuando estudiaba esa región. Después de analizar juntos las imágenes reveladas — señala Zirión-, Nanuk"proponía otros elementos y nuevas escenas para los siguientes días". No cabe duda de que es un texto importante también para el campo de las metodologías constructivistas, pues construye conocimiento, en la acción investigativa, de manera más horizontal. No olvidemos que es la antropología la que más ha aportado en el último tiempo en este terreno a las ciencias sociales en general, sin dejar de reconocer el giro cultural contemporáneo que las atraviesa a todas.

Rocío Rueda Ortiz, académica colombiana consolidada en el campo de la cibercultura y la educación, también colabora en este número con el trabajo titulado "Redes sociales digitales: de la presentación a la programación del yo". Este texto incluye interesantes avances de una investigación en curso, sobre las prácticas digitales de jóvenes universitarios en la red social Facebook. La autora muestra, por un lado, la metodología utilizada: etnografía virtual, entrevistas en profundidad y un modelo de clasificación de imágenes de los perfiles de usuarios específicos, creado para este estudio, y al mismo tiempo el análisis realizado, y una propuesta de pautas para otras investigaciones sobre este nuevo campo. El análisis se aboca a la confluencia, en la red social mencionada, de dos procesos: la transformación, por un lado, de las prácticas del representar/fotografiar y de sus tecnologías y, por el otro, de las formas de producción subjetiva. $Y$ se pone de relieve el pensamiento que se construye en la acción, es decir, una dimensión epistemológica sobre el paradigma del constructivismo actual.

En este texto, Rocío Rueda se interesa por la forma en que los consumidores se apropian de los productos y servicios de la tecnología digital, desde sus usos privados a los sociales; su perspectiva se enfoca en la transformación de la subjetividad. Todo ello cobra mayor relevancia por la articulación de aportes de diferentes escuelas y

3 Voces de la Guerrero, codirigida por Zirón con Adrián Arce y Diego Rivera (2004), recibió el Premio José Rovirosa, otorgado por la unAm, al mejor documental de ese año [http://vocesdelaguerrero.com]. En 2013, con Adrián Arce, codirigió Fuera de foco y recibió, entre otras distinciones, la de Mejor documental en el $5^{\circ}$ Festival Short Shorts México 2014 [http://fueradefocodocumental.com]. 
disciplinas: filosofía política, antropología, cibernética y ciencias sociales, todo ello bajo una mirada foucaultiana.

Rueda se pregunta por la producción de sujetos y subjetividades a través del poder que se debate en la tensión permanente entre el dominio y la resistencia. Este estudio encuentra sustento también en los planteamientos interaccionistas de Goffman. Así, explora si en Facebook los usuarios fabrican su vida personal como una especie de obra de arte (una obra mundana), en particular en lo que se refiere a la imagen de su perfil. Para ello, además de negociar la cultura entre iguales como se hace en la interacción "cara a cara", muestra que también se deben negociar las intenciones y acciones con la "lógica social" que ofrece dicha plataforma digital. De ese modo, una de sus conclusiones es que la identidad es una coproducción en la que se cruzan las estrategias de la plataforma y las tácticas de los usuarios. Y no es posible pensar ese asunto exclusivamente desde la teatralidad y la performatividad propuestas por Goffman.

Rocío Rueda se pregunta por el acceso a las plataformas ya diseñadas y lo que hace el sujeto con ellas y a qué lo conducen esas prácticas. Sus hallazgos indican que lo llevan más que a comunicar y compartir afectos a través de selfies, a afirmarse cada vez más en este mundo individualista. En otras palabras, se interesa en el cyborg actual y su trabajo deriva en reflexiones sobre el tema de la esfera privada y la participación en el espacio público.

Por su parte, Juan Soto ofrece el texto titulado "Nosotros entre las imágenes (o los usos sociales de las imágenes)", en el que explica minuciosamente las diversas lecturas de las fotografías digitales a partir de las imágenes que construye un usuario desde el sentido colectivo que le ofrece, es decir, sentido relacionalmente construido. Soto se posiciona en la psicología social y el estudio del sentido común, y de esa manera pone en tela de juicio que el usuario que no disponga de un aparato crítico, ni afectivo particular, pueda otorgar una mirada significativa y de agrado a la pintura de Frida Kalho, por ejemplo. Soto muestra que no se logra el sentido y menos uno que interpele, si no es compartido, o si no se tiene acceso a él. Las fotos no son lo mismo que las imágenes, o más bien hay diversas imágenes sobre una foto, dependiendo de la cultura y de qué tan significativo le resulte esta como "símbolo" al receptor, quien siempre pertenece a una comunidad de sentidos. Quien hace fotos con su celular no lee estos ensayos sobre la producción de fotos y luego las interpreta, sino que lo hace según el grupo social al que pertenece. Al igual que Zirión, Soto produce imágenes sobre cultura aunque de manera diferente. ${ }^{4}$ En este

4 Autor del documental Mujeres de arena, sobre la lucha libre femenina, ganador en el concurso de 
artículo piensa sobre ellas y las muestra desde su punto de vista disciplinar interesado en la creación de significados en la vida cotidiana. Nos dice que "la estética del presente cibernético no responde a una simple lógica de consumo sino a otra de tipo relacional". De acuerdo a esta lógica, Soto argumenta que la comunicación con imágenes constituye un proceso de creación de realidades en el que diversas perspectivas del sentido común trascienden el ámbito personal. Por ello, lo que hace que cualquier acto sea social es la simbolización que encierra. Así, Soto continúa diciendo, los símbolos son parte del mundo imaginario que comparten los participantes del pacto social. Un signo es compartido porque se convierte en símbolo (realidad psicosocial), de lo contrario no se comprende, ni se le da sentido. Todo lo anterior permite recordar el planteamiento bourdiano sobre el necesario capital cultural para pertenecer a un grupo y, en consecuencia, el poseer o no disposiciones para diversas prácticas o interpretaciones que permitan identificarse con un grupo, "pertenecer", adecuarse a un entorno de aprendizaje, como puede ser el virtual. Todo ello nos lleva a preguntarnos por las prácticas sociales, incluidas las digitales, con contenido emancipatorio, crítico e intercultural.

Este tema central ha sido concebido desde este tipo de interrogantes, y más específicamente situando estas reflexiones en el campo de la educación. Por ello, un antecedente que se articula con ellas es el proyecto de la nueva mirada de la UAM-I: del aula al ciberespacio, en el cual se produjo material digital educativo, dirigido a los usuarios comunes, asistentes a cibercafés populares — por lo general, alumnos de educación media y media superior-, buscando contribuir a la autoformación. En aquel contexto, $y$ con prácticas de acompañamientos presenciales y del material producido por los alumnos en tanto prosumidores y referido a proyectos de investigaciones universitarias (de profesores y alumnos), fue posible hacer una campaña de alfabetización digital en estos espacios del mercado.

Estas investigaciones, y otras, pretenden constituir aportes a la reflexión abierta, a la investigación en curso y a la acción para construir dispositivos más amplios en apoyo a la instalación de tecnologías digitales que integren la voz de los actores implicados junto con otras miradas inteligentes para la producción y lectura de las imágenes en internet, como lo son las investigaciones presentadas en esta ocasión.

Las imágenes construidas fuera de la escuela entran en ella y son las más numerosas. Ingresan por medio de la habilidad tecnológica y la configuración de la pers-

iniciativas ciudadanas comunitarias para la promoción cultural y la comunicación social alternativa del DF 201 en la categoría de cine, TV y videos documentales. Mención especial en el festival Pantalla de Cristal, octubre 20iı, Cineteca Nacional, México, DF. 
pectiva que ello implica. Estas imágenes tienen intenciones y parten de ideologías. Operan constantemente, sin pensar la acción con el teclado, y reproducen el statu quo en aras del afecto. Las imágenes no son solo visuales, tocan todo el espectro sensorial, que es fácilmente manipulable por medio del deseo y la construcción de los imaginarios del mercado. Recordemos lo que han planteado Adrián Scribano e Inés Dussel, retomando a Walter Benjamin respecto de la obra de arte en la era de la reproductibilidad técnica: las emociones que expresan las imágenes son el botín de guerra, pues desde ellas se define lo que es agradable y lo que se rechaza, lo deseable y lo abyecto. Desde ellas se construyen las valoraciones acerca de los diversos acontecimiento sociales.

\section{Bibliografía}

Benjamín, Walter (2003), La obra de arte en la época de su reproductibilidad técnica, Ítaca, México.

Bourdieu, Pierre (1998), La distinción: criterio y bases sociales del gusto, Taurus, Madrid.

Cochet, Herbé (2008), "La formación del sujeto y su complejidad, reflexiones para este espacio/ tiempo digital", en M. C. Fuentes y J. Ortiz, Entre complicaciones y complejidades: mediaciones en el acceso de las TIC en México, Universidad Autónoma Metropolitana-Unidad Xochimilco/ Universidad Autónoma Metropolitana-Unidad Iztapalapa, México.

Colorado, Óscar (2014), Instagram, el ojo del mundo, OscarEnFotos Publishing, México.

Cornejo, Inés y Luis Guadarrama (coords.) (2013), Culturas en comunicación. Entre la vocación intercultural y las tecnologías de información, Productora de Contenidos Culturales Sagahón Repoll, México.

Cortázar, Francisco (2014), "Imágenes rumorales, memes y selfies: elementos comunes y significados", en Iztapalapa, 77, pp. 19I-2I4.

Dorcé, André (2009), “Televisión e Internet: ¿convergencia con un solo sentido?”, en M. A. Aguilar, E. Nivón, M. A. Portal y R. Winocour (coords.) Pensar lo contemporáneo: de la cultura situada a la convergencia tecnológica, Anthropos, Barcelona, pp. 297-310.

(2012),"Televidentes e internautas de la televisión pública en México. Una aproximación desde la convergencia intermedial", Derecho a comunicar, 5, México. 
Dussel, Inés (2009), "La cultura visual contemporánea: política y pedagogías para este tiempo. Entrevista a Nicholas Mirzoeff", Propuesta Educativa, 3I, pp. 69-8I

(en prensa),"Más allá del mito de los nativos digitales, jóvenes, escuela y saberes en la cultura digital”, en M. Southwell (comp.), Entre generaciones. Exploraciones sobre educación, instituciones y cultura, Homo Sapiens, Rosario.

Flichy, Patrice (200I), L" imaginaire d"Internet, La Découvert/Syros, París.

Fuentes, María Cristina (20I0), "Transformaciones de la subjetividad en los jóvenes por el uso masivo de Internet", en M. Liévano, Bifurcaciones de la subjetividad, Universidad Autónoma de Nuevo León, Monterrey. (2012), El edén de los jóvenes: los cibercafés populares, UAM-I/Juan Pablos editores, México.

Herrera, T. N. (2015), Significados y discursos docentes sobre las tecnologías de la información y la comunicación (TIC) en dos secundarias, tesis de maestría inédita, Cinvestav, México.

Rueda, Rocío (2004),"Tecnocultura y sujeto cyborg: esbozos de una tecnopolítica educativa”, en Nómadas, 21, octubre, pp. 70-82.

Scribano, Adrián (2013), Encuentros creativos expresivos: una metodología para estudiar sensibilidades, ESE Editora, Buenos Aires.

Zirión, Antonio, Adrián Arce y Diego Rivera (dirs.) (2004), Voces de la Guerrero, Homovidens, México [DVD]. Disponible en $<$ http://vocesdelaguerrero. com>.

Zirión, Antonio y Adrián Arce (dirs.) (2013), Fuera de foco, Homovidens, Etnoscopio, UAM-I, México [DVD]. Disponible en $<$ http://fueradefocodocumental.com>. 